\title{
A study on clinico-histopathological patterns of ovarian tumors
}

\author{
Vinitha Wills*, Rachel Mathew
}

Department of Obstetrics and Gynaecology, Pushpagiri Institute of Medical Sciences and Research Centre, Thiruvalla, Pathanamthitta, Kerala, India

Received: 06June 2016

Accepted: 01 July 2016

\section{*Correspondence:}

Dr. Vinitha Wills,

E-mail: drvinithajacob@gmail.com

Copyright: ( $)$ the author(s), publisher and licensee Medip Academy. This is an open-access article distributed under the terms of the Creative Commons Attribution Non-Commercial License, which permits unrestricted non-commercial use, distribution, and reproduction in any medium, provided the original work is properly cited.

\section{ABSTRACT}

Background: Ovarian tumors are an increasing cause for morbidity and mortality world over. The objective of this study was to study the distribution of ovarian tumors histopathologically in different age groups and their various clinical presentations.

Methods: Ninety eight patients who presented with 140 ovarian lesions on either or both sides were analyzed during a study period of one year and a further one year follow-up of patients with malignant tumors were done in a Tertiary teaching hospital.

Results: There were 140 lesions comprising of $40 \%$ of neoplastic lesions and $60 \%$ of non-neoplastic lesions. Among the ovarian neoplasms, $91.1 \%$ were benign lesions, $7.1 \%$ malignant and $1.8 \%$ were borderline malignant. Serous tumors were the commonest tumors $(46.4 \%)$ followed by mucinous tumors and germ cell tumors $(23.2 \%$ each). Endometriotic cysts $(34.5 \%)$ were the commonest non-neoplastic lesions. The distribution of benign tumors in the reproductive age groups was only slightly more than that in the perimenopausal age group. All malignant tumors were in the perimenopausal age group. Menstrual complaints like irregular bleeding and menorrhagia formed the majority of clinical presentation. Bilaterality of lesions was seen in 16 patients.

Conclusions: Benign ovarian tumors are common in reproductive age group as well as perimenopausal age group. The most common neoplasm present was surface epithelial tumors - serous tumors followed by germ cell and mucinous tumors. The most common non-neoplastic lesions were endometriotic cysts and inclusion cysts. Bilateral involvement was uncommon with preponderance of lesions on the right side. Common clinical presentations were menstrual problems and abdominal pain.

Keywords: Ovarian neoplasm, Histopathology, Clinical presentation

\section{INTRODUCTION}

Ovarian masses are common forms of neoplasms in women and form some of the most challenging cases in Gynaecology. Ovarian tumors that present in the reproductive age group are mostly benign while about $30 \%$ in the postmenopausal age group are malignant. ${ }^{1}$ They present themselves in various clinical forms and surprisingly many a time as vague, non-gynaecological complaints. Ovarian tumors also present in a wide spectrum of histopathological patterns. Many ovarian tumors are asymptomatic in the early stages and are unfortunately diagnosed in the advanced state. The high mortality rate of ovarian cancer is due to its late detection, thus earning itself the term "Silent Killer". 2

Ninety percent of adnexal masses are detected by pelvic ultrasound. ${ }^{3}$ This provides the clinician information about the origin of the adnexal mass. Further, details of the tumor like its complexity, its vascularity and consistency are made out on ultrasound imaging. The definitive diagnosis of the tumor however is by histopathological study. ${ }^{4,5}$ 
For a clinician, the practical method for screening for an adnexal mass is a bimanual pelvic examination done routinely in the outpatient department. ${ }^{6}$ Tumor markers also help in the identification of ovarian masses. Adjunctive diagnostic techniques like MRI and CT help further in identifying metastasis of the tumor. Recent statistics in developed countries report better survival rates in patients with ovarian tumors; this being due to early detection and early appropriate treatment. ${ }^{7}$

\section{METHODS}

This study was done retrospectively in the department of Obstetrics and Gynaecology at Pushpagiri Institute of Medical Sciences and Research Centre, Tiruvalla, Kerala, South India. There were 98 patients with 140 ovarian masses on either or both sides who were admitted in the department during the period of 1 year (January December 2014). The patients who underwent surgery for ovariotomy alone or along with hysterectomy were included in the study. Ovarian tumors managed conservatively were excluded from the study. Data regarding age, clinical symptoms, details of the mass like size, laterality, per-operative findings and histopathology were collected and statistically studied. Histopathological examination of the specimens was conducted by the department of Pathology of the hospital following appropriate staining (haematoxylin and eosin staining). The histopathological reports (HPR) were based on WHO classification of ovarian tumors. Follow-up of patients with malignant tumors were done post-operatively for a further period of one year. Percentages were calculated in each category and compared.

\section{RESULTS}

A total of 98 patients who presented with 140 ovarian masses on either and/or both sides formed the study group. Among the 140 lesions, there were 56 neoplastic tumors and 84 non-neoplastic lesions.

Among the neoplastic lesions, 91.1\% (51/56) were benign, $7.1 \%$ (4/56) were malignant and there was only $1.8 \%$ (1/56) with borderline malignant histopathology. Maximum number of benign ovarian tumors was in the 21-40 year age group and a similar number in the 41-60 year age group. All the malignant tumors [100\% (4/4)] were in the 41-60 year age group. Serous cyst adenomas (44.6\%), followed by Germ Cell tumors (23.2\%) and mucinous cyst adenoma $(17.8 \%)$ were the most common benign tumors. The rest were 2 cases of Fibroma and 1 case of granulosa cell tumor. Of the 4 malignant tumors, 2 were mucinous cyst adenocarcinoma, 1 each of Serous cystadenocarcinoma and endometrioid adenocarcinoma. The borderline tumor belonged to the Mucinous group.

Among the non-neoplastic masses, commonest was endometriotic cyst $34.5 \%$ (29/84), followed by inclusion cysts $28.5 \%$ (24/84). Abnormal menstrual patterns followed by abdominal pain were the major presenting symptoms in these patients.

Among the malignant tumors, those that were diagnosed peroperatively as stage I (mucinous cystadenocarcinoma 2) were managed with curative surgery. Another found as stage II b (serous cystadenocarcinoma) had surgery followed by six cycles of chemotherapy. At the end of one year follow-up, these patients are doing well. The case of endometrioid adenocarcinoma was lost to followup.

\section{DISCUSSION}

Developed countries show ovarian carcinoma as the cause of $30 \%$ of malignancies of the female genital tract. ${ }^{8}$ In this study, out of 140 ovarian lesions, $96.4 \%$ were benign (135/140), $2.8 \%$ (4/140) were malignant and $0.7 \%$ (1/140) were borderline malignant tumor.

Table 1: Histopathological distribution of ovarian neoplasms.

\begin{tabular}{|lll|}
\hline Histopathology of tumors & $\begin{array}{c}\text { No. of } \\
\text { neoplasms }\end{array}$ & Percentages \\
\hline Surface epithelial tumors & $\mathbf{4 0}$ & $\mathbf{7 1 . 4}$ \\
\hline Serous tumor & $\mathbf{2 6}$ & $\mathbf{4 6 . 4}$ \\
\hline Serous cyst adenoma & 25 & 44.6 \\
\hline Serous cyst adenocarcinoma & 1 & 1.8 \\
\hline Mucinous tumors & $\mathbf{1 3}$ & $\mathbf{2 3 . 2}$ \\
\hline Mucinous cyst adenoma & 10 & 17.8 \\
\hline Mucinous cyst adenocarcinoma & 2 & 3.6 \\
\hline Borderline mucinous cyst & 1 & 1.8 \\
adenocarcinoma & & $\mathbf{1 . 8}$ \\
\hline Endometrioid adenocarcinoma & $\mathbf{1}$ & $\mathbf{2 3 . 2}$ \\
\hline Germ cell tumor & $\mathbf{1 3}$ & 21.4 \\
\hline Benign cystic teratoma & 12 & 1.8 \\
\hline Struma ovary & 1 & $\mathbf{5 . 3}$ \\
\hline Sex cord stromal tumor & $\mathbf{3}$ & 3.6 \\
\hline Fibroma & 2 & 1.8 \\
\hline Granulosa cell tumor & 1 & \\
\hline
\end{tabular}

(No. of Neoplastic lesions $=56$ ).

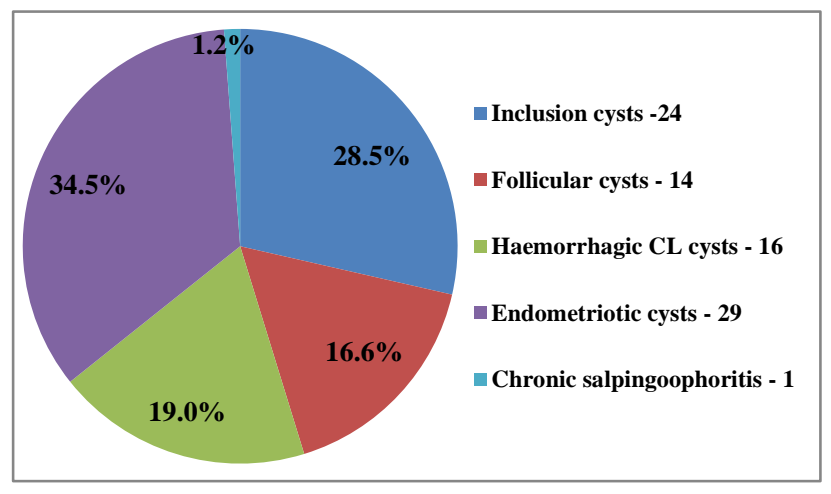

Figure 1: Distribution of non-neoplastic lesions $(n=84)$. 
Ovarian tumors show histological heterogeneity. The WHO classification of ovarian tumors is based on the tissue of origin - epithelial, germ cell tumors, sex cord stromal tumors. ${ }^{8}$ It is globally seen that, surface epithelial tumors are the most common ones. ${ }^{1}$ This study also is in favour of that observation (Table 1). Epithelial tumors formed $71.4 \%(40 / 56)$ the main bulk of neoplasms observed in the study. The majority of epithelial tumors were serous tumors $(46.4 \%)$ and mucinous and germ cell tumors (23.2\% each). Among serous tumors, serous cyst adenoma constituted $44.6 \%$ and serous cyst adenocarcinoma was $1.8 \%$. Among mucinous tumors, $17.8 \%$ were cyst adenoma, $3.6 \%$ were cyst adenocarcinomas and $1.8 \%$ with borderline pathology. There was one patient who was diagnosed to have endometrioid adenocarcinoma. Among the germ cell tumors, all were benign cystic teratomas with one having a predominance of thyroid tissue (struma ovary).

Table 2: Distribution of ovarian masses in different age groups.

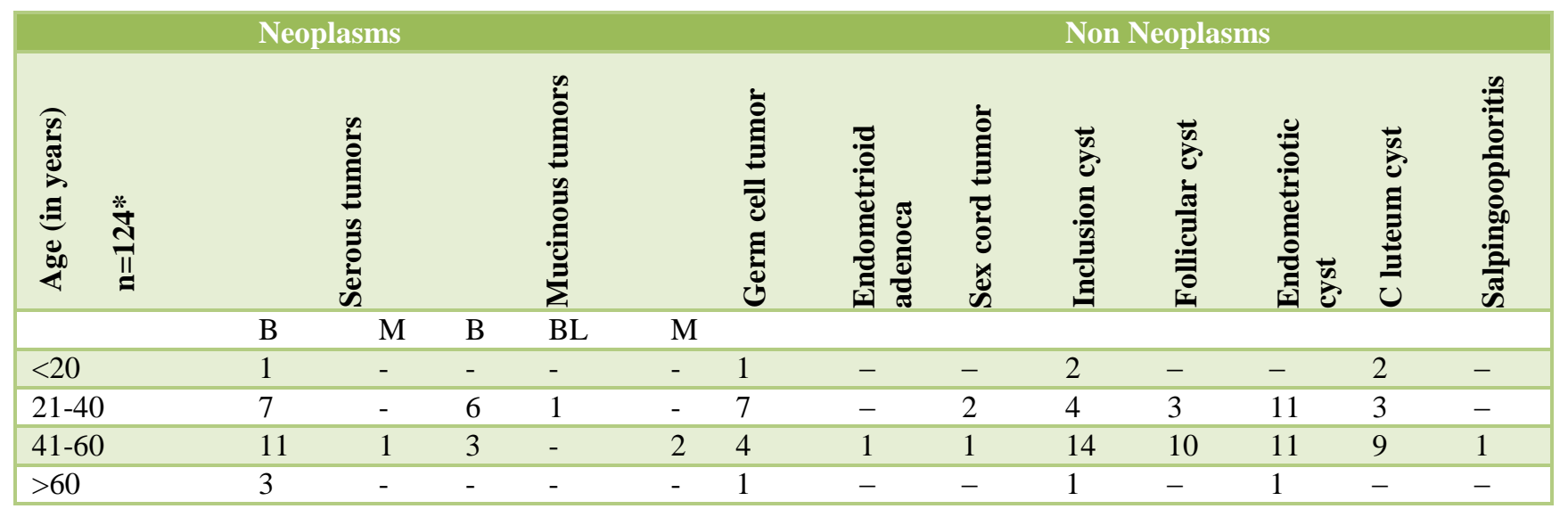

$\mathrm{B}=$ Benign; $\mathrm{M}=$ Malignant; $\mathrm{BL}=$ Borderline; * Frequency of occurance in an age-group taken as 1 in individuals with the same lesion bilaterally.

The frequency of distribution of ovarian tumors in the present study was similar to that as reported by Swami G $\mathrm{G}$ et al. They reported an incidence of $61.6 \%$ of epithelial tumors and $21.7 \%$ of germ cell tumors. ${ }^{9}$ This was in concordance with the study by Mondal who reported surface epithelial tumors to be the most common $(67.9 \%)$ and germ cell tumors (23.1\%). ${ }^{10}$ Gupta $\mathrm{N}$ and Ahmad Z reported similar high incidences - $98.8 \%$ and $63.5 \%$ respectively, in their studies. ${ }^{11,12}$ Thanikasalam who conducted a study among Asian population reported the most common ovarian neoplasm among Indians to be Serous cystadenoma and Teratomas among the Malay and Chinese. ${ }^{13}$ Among the non-neoplastic lesions, 34.5\% were endometriotic ovarian cysts, thus explaining the predominant complaint of menstrual problems at presentation. A similar high incidence of ovarian endometriosis $(45.9 \%$ ) was observed by Al-Fozan $\mathrm{H}$ and Tulandi T. ${ }^{14}$ Contradicting this were studies by Gupta N and Carey $\mathrm{M}$ who reported low incidences. ${ }^{11,15}$

In this study (Table 2), benign tumors were more in the reproductive age group (21-40 years). A similar number of benign tumors were also seen in the perimenopausal group (41-60 years). All 4 patients diagnosed with malignant ovarian tumors were in the older group (41-60 years). The single borderline tumor was present in the younger group (21-40 years). Manivasakan J observed an equal distribution of benign ovarian tumors in the reproductive and perimenopausal age groups. ${ }^{16}$ Sharadha SO noted maximum number of neoplasms $89.9 \%$ in the reproductive age group which was comparable to that reported by Ashraf A et al. ${ }^{17,18}$ On the contrary, Ashraf's study reported a high percent $(71.4 \%)$ of malignant tumors in the reproductive age group. Most of available literature from the western world report ovarian cancer to be more in the elderly perimenopausal women. ${ }^{19,20}$ Studies from India and Pakistan found the occurrence of ovarian tumors to be unusual before the age of 40 years. $^{21,22}$ Germ cell tumors $53.8 \%$ (7/13) were more in the 21-40 year group and not as expected in the adolescent group. Surface Epithelial Tumors (SET) were there in both reproductive and perimenopausal age groups. ${ }^{21,22}$ Endometriotic cysts and inclusion cysts were more in the 40-60 year group. These findings were comparable to that of Mankar. ${ }^{23}$

Common clinical presentations in this study for both neoplastic and non-neoplastic lesions were menstrual complaints (Figure 2). Menstrual problems common in the reproductive age groups like irregular bleeding, menorrhagia, and dysmenorrhoea was reported by 27 patients and 6 complained of post-menopausal bleeding. Endometriotic lesions (34.5\%) could have attributed to this uncommon complaint in ovarian masses. Patient with endometrioid adenocarcinoma also presented with bleeding irregularities. A good number of ovarian masses 
were diagnosed incidentally - during histopathological examination of hysterectomy and salpingoophorectomy specimens. Three pregnant women were diagnosed as having ovarian masses during routine antenatal ultrasound. Laparotomy done for a case of ruptured ectopic pregnancy showed associated endometriotic cyst. Abdominal pain and back pain were reported by 21 of our patients. Cause of this abdominal pain was due to torsion only in 2 patients. One patient had chronic salpingoophoritis and another case operated for an endometriotic cyst was found to have formed an abscess. Endometriotic ovarian cysts were seen in many of patients who presented with infertility (5.1\%). Gastrointestinal symptoms like dyspepsia, nausea and vomiting, usually more in malignant tumors were present in both groups. The small number of malignant tumors in this study could be the reason for this discrepancy.

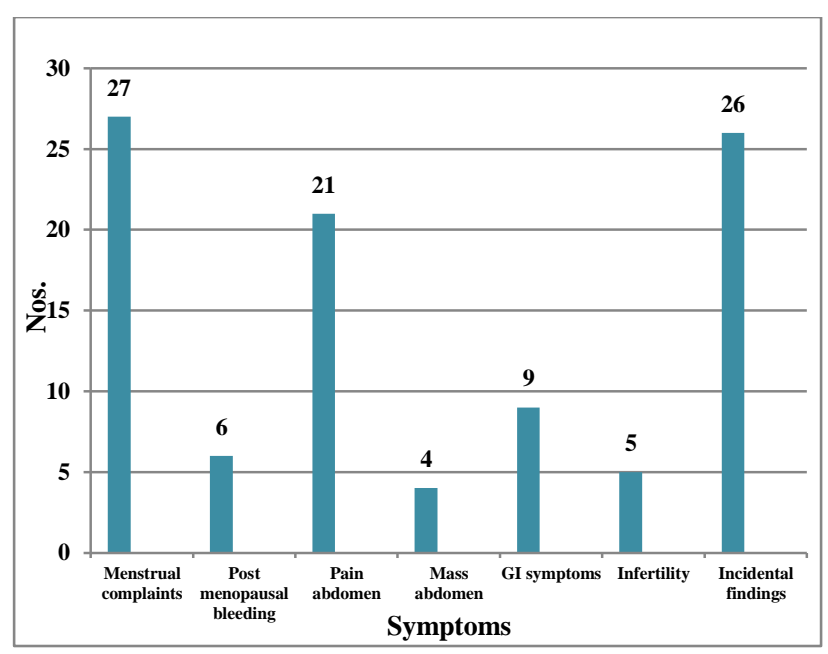

Figure 2: Clinical presentation of patients.

Patients have presented with more than one symptom.

Table 3: Distribution of laterality and size of ovarian lesions.

\begin{tabular}{|c|c|c|c|c|c|c|c|}
\hline \multirow[b]{2}{*}{ 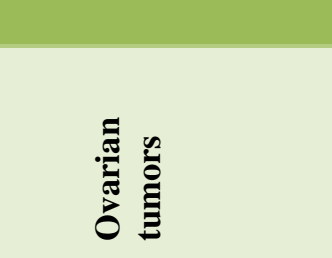 } & \multicolumn{3}{|c|}{ Side } & \multicolumn{4}{|c|}{ Size } \\
\hline & $\frac{\underbrace{}_{0}}{a 0}$ & $\stackrel{\varpi}{\varrho}$ & 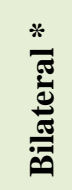 & $\begin{array}{l}\Xi \\
0 \\
\dot{\nabla}\end{array}$ & $\begin{array}{l}\Xi \\
0 \\
\hat{\theta} \\
\text { in }\end{array}$ & $\begin{array}{l}\Xi \\
\vdots \\
\dot{J} \\
\dot{d}\end{array}$ & 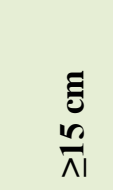 \\
\hline Serous & 13 & 7 & 3 & $6(4.3)$ & $16(11.4)$ & $4(2.8)$ & - \\
\hline Mucinous & 8 & 3 & 1 & $2(1.4)$ & $3(2.1)$ & $4(2.8)$ & $4(2.8)$ \\
\hline $\begin{array}{l}\text { Endometrioid } \\
\text { adenocarcinoma }\end{array}$ & 1 & - & - & - & $1(0.7)$ & - & - \\
\hline Germ cell & 8 & 5 & - & $5(3.6)$ & $6(4.3)$ & $2(1.4)$ & - \\
\hline Sex cord stromal tumor & - & 3 & - & $2(1.4)$ & $1(0.7)$ & - & - \\
\hline Inclusion cyst & 13 & 5 & 3 & $20(14.3)$ & $4(2.8)$ & - & - \\
\hline Follicular cyst & 7 & 5 & 1 & $14(10.0)$ & - & - & - \\
\hline $\begin{array}{l}\text { Haemorrhagic corpus } \\
\text { luteal cyst }\end{array}$ & 5 & 7 & 2 & $15(10.7)$ & $1(0.7)$ & - & - \\
\hline Endometriotic cyst & 8 & 9 & 6 & $17(12.1)$ & $9(6.4)$ & $1(0.7)$ & $2(1.4)$ \\
\hline $\begin{array}{l}\text { Chronic salpingo- } \\
\text { oophoritis }\end{array}$ & - & 1 & - & - & $1(0.7)$ & - & - \\
\hline \multirow[t]{2}{*}{ Total } & 61 & 47 & 16 & 81 & 42 & 11 & 6 \\
\hline & $=124$ & & & $n=140$ & & & \\
\hline
\end{tabular}

* Only lesions with the same histopathology on both sides have been included.

Mankar DV reported only 5\% of menstrual abnormalities. However non-neoplastic lesions like endometriotic cysts were not taken into consideration. ${ }^{23} \mathrm{He}$ observed other common presentations of abdominal pain and lump. A notable fact was that abdominal pain was present equally in both malignant and benign groups. Interestingly, 43\% of abdominal masses were associated with benign lesions. $^{23}$ Findings similar to our study regarding menstrual complaints and abdominal pain were seen by Kanthikar SN and Winter Jo TV. ${ }^{24,25}$ Abdominal pain was seen to be associated with $90 \%$ ovarian tumors in certain studies which also reported $66 \%$ of abdominal masses to be associated with malignant ovarian tumors.

This study showed 16 cases of bilateral involvement of ovarian tumors with the same histopathology (Table 3). Majority of tumors were found to be on the right side. The low number of malignant ovarian tumors attributed to the decreased incidence of bilateral involvement of ovarian tumors in this present study. Studies conducted 
by Mondal showed that bilateral ovarian tumors were usually malignant in nature. Bilaterality was seen in $49.5 \%$ of malignant serous tumors and $28.1 \%$ of mucinous tumors. ${ }^{10}$ Literature from Nepal shows that bilateral occurence of ovarian masses was a rare finding in their population. ${ }^{16,26}$ Size of the ovarian masses in our study ranged from $1 \mathrm{~cm}$ to the largest being $22.5 \mathrm{~cm}$ (Table 3). Most of the masses less than $5 \mathrm{~cm}$ were nonneoplastic lesions and the large ones $(>15 \mathrm{~cm})$ belonged to the mucinous and endometriotic lesions.

\section{CONCLUSION}

Benign ovarian neoplasms were seen similarly in both reproductive and perimenopausal age groups. Malignant tumors were all in the postmenopausal group. Based on histopathology, most common neoplasm was surface epithelial tumors - serous tumors, then mucinous and germ cell tumors. Most common non-neoplastic lesion was endometriotic cysts. Ovarian masses were more on the right side with only few showing bilateral involvement. Menstrual problems and abdominal pain were the common clinical presentation seen. Differentiation of a benign tumor from a malignant one is important for determining management and prognosis; hence further similar studies are warranted.

\section{ACKNOWLEDGEMENTS}

The authors would like to thank Dr. N S Sreedevi, Professor and Head, Department of Obstetrics and Gynaecology, Pushpagiri Institute of Medical Sciences and Research Centre, Thiruvalla, Kerala. And Dr. M O Annamma, Professor and Head, Department of Pathology, Pushpagiri Institute of Medical Sciences and Research Centre, Thiruvalla, Kerala.

Funding: No funding sources

Conflict of interest: None declared

Ethical approval: Not required

\section{REFERENCES}

1. Berek JS, Natarajan S. Ovarian and fallopian tube cancer. In: Berek JS (Editor). Berek and Novak's Gynaecology $15^{\text {th }}$ Ed. Wolter Kluwer Health (India) Private Limited; 2012:1350-1427.

2. Jaffer Y, Ehsan N, Ambreen. Clinical presentation of ovarian tumors. Journal of Surgery Pakistan (International). 2013;18(2):82-6.

3. Brown DL, Dudiak KM, Laing FC. Adnexal masses: US characterization and reporting. Radiology. 2010;254(2):342-54.

4. Gentry-Maharaj A, Menon U. Screening for ovarian cancer in the general population. Best Pract Res Clin Obstet Gynaecol. 2012;26:243-56.

5. Attunueci CA, Ball HG, Zweizig SL, Chen AH. Differences in symptoms between patients with benign and malignant ovarian neoplasms. Am J Obstet Gynecol. 2004;190:1435-7.
6. Rock JA, Jones HW. Ovarian cancer; etiology, screening and surgery. Te Linde's Operative Gynaecology, $10^{\text {th }}$ Ed., Lippincott Williams and Wilkins; 2011:1307-1339.

7. Coleman MP, Estere J, Damiecki P. Trends in Incidence and Mortality, Lyon, IARC. 1993;121:1801.

8. Seshadri L. Malignant diseases of the ovary and fallopian tube. In: Essentials of Gynaecology, $1^{\text {st }} \mathrm{Ed}$. Wolters Kluwer (India) of Lippincot Williams and Wilkins; 2011:418-440.

9. Swamy GG, Satyanarayana N. Clinicopathological analysis of ovarian tumor - a study on five year samples. Nepal Med Coll J. 2010;12(4):221-3.

10. Mondal SK, Bandopadhyay R, Nag DR, Roychowdhury S, Mondal PK, Sinha SK. Histological pattern, bilaterality and clinical evaluation of 957 ovarian neoplasms. A 10 year study in a tertiary hospital of Eastern India. J Can Res Ther. 2011;7:433-7.

11. Gupta N, Bisht D, Agarwal AK, Sharma VK. Retrospective and prospective study of ovarian tumors and tumor - like lesions. Indian J Pathol Microbiol. 2007;50:525-7.

12. Ahmad Z, Kayani N, Hasan SH, Muzaffar S, Gill MS. Histological pattern of ovarian neoplasm. J Pak Med Assoc. 2000;50:416-9.

13. Thanikasalam K, Ho CM, Adeed N, Shahidan MN, Azizah WK. Links pattern of ovarian tumors among Malaysian women at General Hospital, Kaula Lumpur. Med J Malaysia. 1992;47:139-46.

14. Al-Fozan H, Tulandi T. Left lateral predisposition of endometriosis and endometrioma. Obstet Gynaecol. 2003;101:164-6.

15. Carey M, Krik ME. Necrotic pseudoxanthomatous nodules of the omentum and peritoneum. A peculiar reaction to endometriotic cyst contents. Obstet Gynaecol. 1993;82:65-52.

16. Manivasakam J, Arounssalame B. A study of benign adnexal masses. Int $\mathrm{J}$ Reprod Contracept Obstet Gynecol. 2012;1(1):12-6.

17. Sharadha SO, Sridevi TA, Renukadevi TK, Gowri R, Binayak D, Indira V. Ovarian masses: changing clinico histopathological trends. The Journal of Obstetrics and Gynaecology of India. 2015;65(1):348 .

18. Ashraf A, Shaikh S, Ishfaq A. The relative frequency and histopathological pattern of ovarian masses. Biomedica. 2013;28:98-102.

19. Poole J, Nordin A. Trent cancer registry. Profile of ovarian cancer in England; 2012.

20. Quirk JT, Natarajan N. Ovarian cancer incidence in the United States 1992-1999. Gynaecol Oncol. 2005;97:519-23.

21. Shah $\mathrm{S}$, Hishikar VA. Incidence and management of Ovarian tumours. Bombay Hospital J. 2008;50:30-3.

22. Wasim T, Majrroh A, Siddiq S. Comparison of clinical presentation of benign and malignant ovarian tumors. J Pak Med Assoc. 2009;59:18-21. 
23. Mankar DV, Jain GK. Histopathological profile of ovarian tumors: a twelve year institutional experience. Muller J Med Sci Res. 2015;6:107-11.

24. Kanthikar SN, Dravid NV, Deore PN, Nikumbh DB, Suryawanshi KH. Clinico-histopathological analysis of neoplastic and non-neoplastic lesions of the ovary: a 3 year prospective study in Dhule, North
Maharashtra, India. Journal of Clinical and Diagnostic Research. 2014;8(8):FCO4-FCO7.

25. Winter Jo TV, Simmons PS, Podratz C. Surgical treated adnexal masses in infancy, childhood and adolescence. Am J Ostet Gynecol. 1994;170:1780-9.

26. Jha R, Karki S. Histological pattern of ovarian tumors and their age distribution. Nepal Med Coll J. 2008; $10: 81-5$.

Cite this article as: Wills V, Mathew R. A study on clinico-histopathological patterns of ovarian tumors. Int J Reprod Contracept Obstet Gynecol 2016;5:2666-71. 